\title{
The use of educational video to promote maternal self-efficacy in preventing early childhood diarrhoea
}

\author{
Emanuella Silva Joventino PhD in Nursing ${ }^{1}$ | Lorena Barbosa Ximenes PhD in Nursing ${ }^{2}$ । \\ Jardeliny Corrêa da Penha PhD Student in Nursing ${ }^{3}$ । Lucilande Cordeiro de Oliveira Andrade \\ MSc in Nursing ${ }^{2}$ । Paulo César de Almeida PhD in Public Health ${ }^{4}$
}

\footnotetext{
${ }^{1}$ Nursing School, University of International Integration of African-Brazilian Lusophony, Redenção, Ceará, Brazil

${ }^{2}$ Nursing School, Federal University of Ceará, Fortaleza, Ceará, Brazil

${ }^{3}$ Nursing School, Federal University of Piauí, Floriano, Piauí, Brazil

${ }^{4}$ State University of Ceará, Fortaleza, Ceará, Brazil

\section{Correspondence}

Jardeliny Corrêa da Penha, Nursing School, Federal University of Piauí, Coelho Rodrigues Street, 350, Ibiapaba, 64.800-000, Floriano-PI, Brazil.

Email: jardelinypenha@yahoo.com.br
}

\begin{abstract}
Diarrhoea is responsible for high rates of infant morbidity and mortality. It is multifactorial, manifested by socioeconomic, hygienic, and maternal factors. The aim of this study is to evaluate the effects of an educational video on maternal self-efficacy for the prevention of childhood diarrhoea. This was a randomised trial conducted in the state of Ceará, Brazil. Participants were 2 groups (comparison and intervention), composed of mothers of children under 5 years of age. Group membership was allocated by cluster randomization. Outcomes were maternal selfefficacy measured using the Maternal Self-efficacy Scale for Prevention of Early Childhood Diarrhoea; outcome data collectors were blinded to group allocation. Ninety participants were randomised to each group; 83 intervention group and 80 comparison group members were contained in the final analysis. Maternal self-efficacy in preventing childhood diarrhoea increased in both groups, but average scores of the intervention group were higher at all time than those of the comparison group. The educational video had a significant effect on maternal self-efficacy.

KEYWORDS

children, diarrhoea, education, maternal behaviour, nursing, self-efficacy
\end{abstract}

\section{SUMMARY STATEMENT}

What is already known about this topic?

- Diarrhoea is responsible for high prevalence of infant morbidity and mortality.

- There is a need to study how mothers feel able to prevent early childhood diarrhoea.

- Few studies test the effectiveness of educational interventions on maternal self-efficacy for preventing early childhood diarrhoea.

What this paper adds?

- Maternal self-efficacy for prevention of early childhood diarrhoea increased more in the group that received an educational video.

- Self-efficacy scores for the group that received the educational intervention were higher at every time than those of the group that did not view the video.
The implications of this paper:

- The video was effective to promote maternal self-efficacy in preventing childhood diarrhoea.

- The video could be integrated into the educational practices of nurses to promote children's health.

- This educational technology may contribute to reduce infant morbidity and mortality.

\section{1 | INTRODUCTION}

Diarrhoea contributes significantly to morbidity and mortality rates in childhood, although it is preventable through low-cost interventions. It is estimated that 1.2 million children die of diarrhoea under the age of 5 years worldwide (United Nations Children's Fund, 2012a); along with pneumonia, these conditions are the cause of 
$29 \%$ of deaths in childhood, causing the loss of more than 2 million young lives every year (World Health Organization, 2013). In the northeast region of Brazil alone, according to 2000-2010 data released by the Ministry of Health, 22933 under 5-year-old children died due to CID A09 (the ICD-10 code for diarrhoea and gastroenteritis, $80.3 \%$ in under 1-year-old children), and there were 1209622 hospitalizations (62.6\% of children between 1 and 4 years old) (Mendes, Ribeiro, \& Mendes, 2013).

In 2009, the United Nations Children's Fund and World Health Organization prepared a report aimed to sensitize countries about this issue and to establish a global action plan to reduce the incidence and mortality associated with the disease (United Nations Children's Fund, 2009). In 2012, United Nations Children's Fund issued another call for action on pneumonia and diarrhoea, aimed to combat these most deadly diseases for children, especially in poorer countries and called on countries for a redirection of efforts to reduce deaths from diarrhoea (United Nations Children's Fund, 2012b). However, what was needed was more than a catalogue of proven effective interventions to reduce the burden of childhood diarrhoea; it was essential that these strategies had good acceptability and coverage (Isanaka, Elder, Schaefer, et al., 2012).

Studies show that many mothers do not have adequate knowledge and skills in the management of childhood diarrhoea. Cross-sectional research conducted with 348 mothers in Jordan found that the vast majority did not know how to use the oral rehydration solution (ORS) during an episode of diarrhoea. Nurses and other health professionals can play an important role in women's education in relation to the management of diarrhoea in their children, as well as regarding the prevention of this condition (Abu-Baker, Gharaibeh, Al-Zoubi, et al., 2012).

For this reason and taking into account the behavioural factors involved in the pathogenesis of diarrhoea in children, the present study developed an educational video in to assist mothers in preventing childhood diarrhoea. Facing the practicality of dissemination of audiovisual information, it was decided to add into the video preventive measures in diarrhoea management skills, such as the preparation of the ORS, infant feeding during diarrhoeal periods, and the danger signs for return of the child to the health system.

\section{2 | METHOD}

\section{1 | Aim}

The aim of this study is to evaluate the effects of an educational video on maternal self-efficacy for the prevention of childhood diarrhoea.

\section{2 | Design}

This was a randomised clinical trial with mothers of children living in 2 different areas ( $\mathrm{A}$ and $\mathrm{B}$ ), enrolled in a Primary Care Health Centre (Union for African Population Studies [UAPS]), in Ceará, in the northeast of Brazil. The care of residents of these 2 neighbourhoods took place in the UAPS on different days of the week.

\section{3 | Sample/participants}

Inclusion criteria were mothers with at least 1 child under the age of 5 years and who had a phone number for further contact, for study follow-up.

Exclusion criteria were mothers who had any cognitive limitations that could prevent them from participating in the educational intervention or answering the evaluation instrument. As criteria for discontinuation in the study: any mother or child's death during the months of data collection; change of the phone number without prior notice to the researchers.

To calculate the sample size, we use the formula for studies with comparative groups with 2 experimental means (Arango, 2009), requiring a sample of 150 participants. An additional margin of $20 \%$ was allowed for dropout, producing a final sample estimated at 180 participants, 90 mothers in the intervention group (IG), and 90 in the comparison group (CG), as shown in Figure 1. By study end, 83 mothers remained in the IG and 80 mothers in the CG, due to sample loss caused by phone out of range, the device no longer belonged to the participant, or even, due to the device not being in the mother's possession at the time of the calls.

The composition of the groups was allocated by cluster randomization, to reduce the probability of the experimental group discussing their educational activity experiences with the mothers of the CG (Cullum, Ciliska, Haynes, et al., 2010). Each neighbourhood was allocated to either the intervention or CG, such that the mothers living in neighbourhood A were allocated to the CG and mothers from neighbourhood $B$ to the IG. The selection of mothers within each group was by convenience sampling, with recruitment of participants conducted by invitation of the community health agents, with attendance at the UAPS specified for different days for the 2 groups.

\section{3 | DATA COLLECTION}

Two instruments were used: the Maternal Self-efficacy Scale for Prevention of Early Childhood Diarrhoea (in Portuguese: Escala de Autoeficácia Materna para Prevenção da Diarriea Infanil-EAPDI; Joventino, Ximenes, Almeida, et al., 2012) and a form (Joventino, 2013) that addressed the demographic profile and socioeconomic and health conditions. The EAPDI has the domains of family hygiene and eating habits/general practices, with 15 and 9 items, respectively; responses ranged from 1 (strongly disagree) to 5 (totally agree), and the total scale scores could range from 24 to 120. Content Validity Index was reported for the EAPDI of 0.96 and Cronbach a of 0.84 (Joventino et al., 2012).

Data were collected in 4 stages for the IG and CG simultaneously: stage 0 (SO), the EAPDI and the form were completed; the EAPDI only was repeated in stage 1 (S1: a month after the first application of the scale); stage 2 (S2: two months), and stage 3 (S3: three months after the first application). At S0, instruments were conducted personally in the UAPS; for the other stages, data were collected through telephone contact.

The instruments were applied by trained staff who did not know which mothers belonged to the intervention or CGs. 


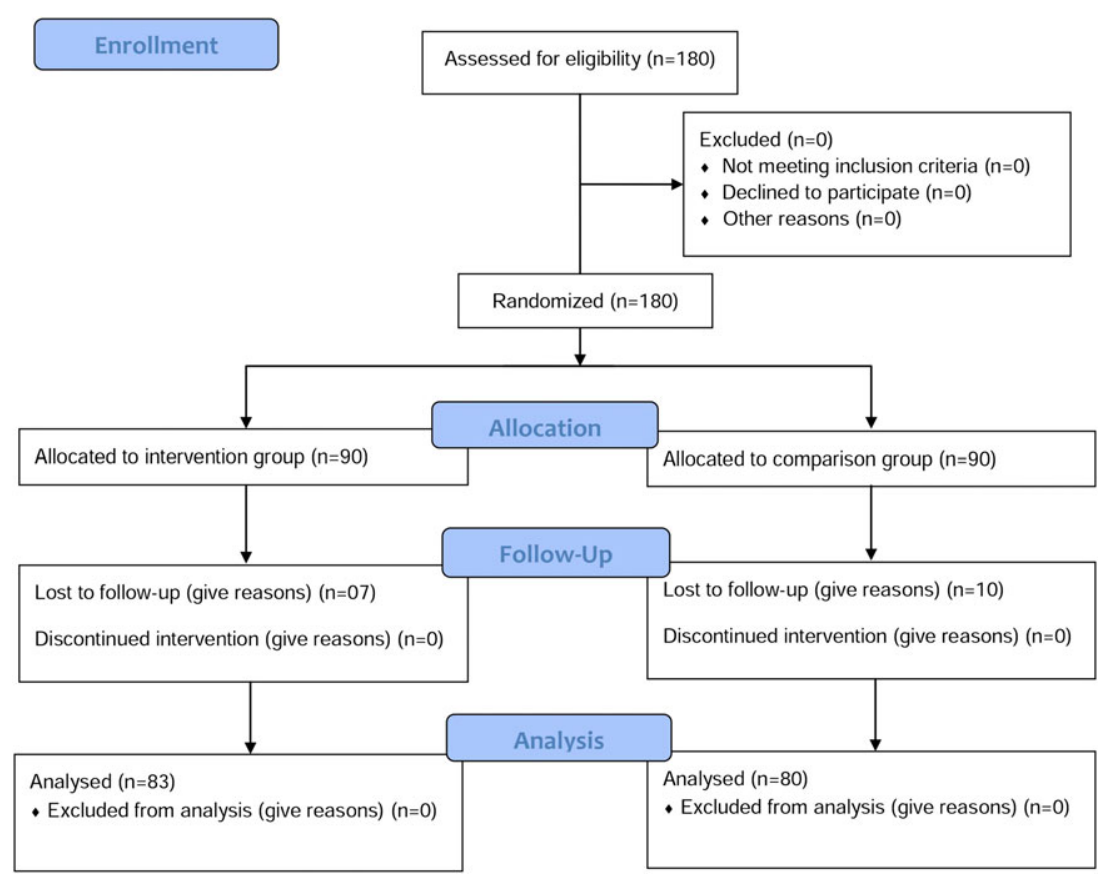

FIGURE 1 Flow diagram CONSORT

In the IG, after S0, the 16-minute educational video "Childhood diarrhoea: you are able to prevent" (Joventino, 2013), which had previously been validated, was presented to the mothers in a private room in the UAPS, with a portable DVD player and a 21-inch TV, for a maximum of 10 viewers per session. No additional guidance related to childhood diarrhoea was provided by any of the researchers.

\section{1 | Ethical considerations}

The study considered the ethical aspects of research involving humans, according to the resolution no. 466/2012 of the National Health Council, and was approved by the Research Ethics Committee of the Federal University of Ceará, protocol no. 106/12.

\section{2 | Data analysis}

The results were presented in tables and graphics. The mean and standard error of the mean of scale values were calculated. Student independent $t$ test was used to compare the means of the 2 groups within each stage; Student $t$ test for dependent data was used to compare the means of each group between the stages S0, S1, S2, and S3. Significance was set at 5\%. Data were processed using SPSS version 20 .

\section{4 | RESULTS}

\section{1 | Characteristics of the participants}

The total initial sample $(n=180)$ was allocated to 2 groups: comparison $(\mathrm{n}=90)$ and intervention ( $\mathrm{n}=90$ ); data obtained at stage S0 were used to check the homogeneity of the sample between the groups. There was no difference between the intervention and CGs regarding maternal age $(P=.708)$, maternal education $(P=.300)$, marital status $(P=.570)$, occupation $(P=.615)$, child gender $(P=.196)$, income per capita $(P=.542)$, number of children $(P=.801)$, origin of water intended for human consumption $(P=.587)$, treatment of the water ingested by the child $(P=.557)$, child prematurity $(P=.481)$, previous diarrhoea episode in the child $(P=.435)$, and rotavirus vaccine $(P=.237)$. Groups were similar regarding the initial maternal selfefficacy scores $(P=.115)$.

\subsection{Comparison of self-efficacy in preventing childhood diarrhoea}

Maternal self-efficacy in preventing childhood diarrhoea increased in both groups (comparison and intervention) over the months, with a slight decrease in the third month of follow-up. Mean EAPDI scores of the IG were at all time higher than those of the CG (Figure 2).

During the 4 stages of monitoring of the study mothers, average scores for maternal self-efficacy in the prevention of childhood diarrhoea rose significantly in both groups $(P<.0001)$. Comparing average EAPDI scores between the groups and within stages, differences were statistically significant at stage 2 , ie, in the second month of follow-up of the mothers $(P=.042)$. The difference in maternal self-efficacy scores at this stage represented a difference of 3.1 between groups (Table 1 ).

Regarding the average scores for the EAPDI domains, the groups were similar at all times, with $P$ values not statistically significant except for the domain of food/general practices, which was significantly different in the first month (S1) of follow-up $(P=.036)$ (Table 2).

\section{5 | DISCUSSION}

For this randomised controlled trial, homogeneity between comparison and IGs was tested, and groups were shown to be similar, providing 


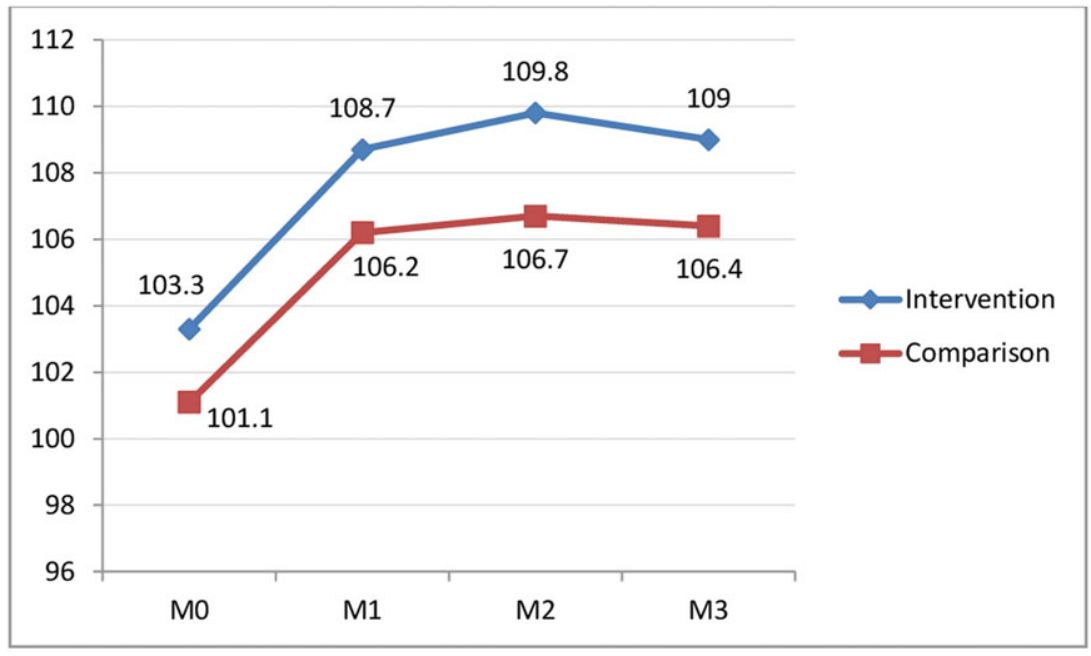

FIGURE 2 Averages of the scores on the Escala de Autoeficácia Materna para Prevenção da Diarriea Infanil according to the group (intervention and comparison) according to each analysed moment

TABLE 1 Comparison of the average EAPDI scores by stage and group

\begin{tabular}{|c|c|c|c|c|c|}
\hline \multirow[b]{2}{*}{ Stage } & \multicolumn{2}{|c|}{ Comparison Group } & \multicolumn{2}{|c|}{ Intervention Group } & \multirow[b]{2}{*}{$P$ Value $^{a}$} \\
\hline & Average & MSE & Average & MSE & \\
\hline so & 101.1 & 9.8 & 103.3 & 9.6 & 0.115 \\
\hline S1 & 106.2 & 10.2 & 108.7 & 9.5 & 0.106 \\
\hline S2 & 106.7 & 10.0 & 109.8 & 9.5 & 0.042 \\
\hline S3 & 106.4 & 10.6 & 109.0 & 9.6 & 0.102 \\
\hline \multicolumn{3}{|c|}{$P$ value $^{b}<.0001$} & \multicolumn{2}{|c|}{$\begin{array}{c}P \\
\text { value }^{\mathrm{b}}<.0001\end{array}$} & \\
\hline
\end{tabular}

Abbreviations: EAPDI indicates Escala de Autoeficácia Materna para Prevenção da Diarriea Infanil; MSE, mean standard error.

${ }^{a}$ Comparing average scores between groups and within stages.

${ }^{\mathrm{b} C o m p a r i n g}$ average scores between stages and within each group. assurance that later differences between the groups were really due to the intervention and not selection bias.(Sampieri, Collado, \& Lucio, 2006) Therefore, the variation in the EAPDI scores was a result of the educational intervention mediated through the video "Childhood diarrhoea: you are able to prevent" for the IG over the 3 months of follow-up, and especially at S2 $(P=.042)$.

Self-efficacy should be evaluated periodically to check the effects of the experiences on personal competence, because the relation between self-efficacy and action is affected by time. Thus, strong self-efficacy beliefs are products of the time and multiple experiences, and weak beliefs require constant reevaluation, to serve as indicators for future interventions (Bandura, 2012). Other follow-up studies have also highlighted the educational intervention's effect in the second month after the strategy, with a focus on

TABLE 2 Comparison of average scale scores and domain scores by group and stage

\begin{tabular}{|c|c|c|c|c|c|}
\hline \multirow[b]{3}{*}{ Stage } & \multicolumn{5}{|c|}{ Group } \\
\hline & \multicolumn{2}{|c|}{ Comparison } & \multicolumn{2}{|c|}{ Intervention } & \multirow{2}{*}{$\begin{array}{l}P \\
\text { Value }\end{array}$} \\
\hline & Average & MSE & Average & MSE & \\
\hline Total scale & 101.1 & 1.0 & 103.3 & 0.9 & 0.115 \\
\hline Domain family hygiene & 64.9 & 0.7 & 65.9 & 0.6 & 0.289 \\
\hline Total scale & 106.2 & 1.1 & 108.7 & 1.0 & 0.106 \\
\hline Domain family hygiene & 67.2 & 0.7 & 68.0 & 0.7 & 0.472 \\
\hline Domain eating habits/general practices & 39.1 & 0.5 & 40.5 & 0.4 & 0.036 \\
\hline \multicolumn{6}{|l|}{ Stage 2 (S2) } \\
\hline \multicolumn{6}{|l|}{ Stage 3 (S3) } \\
\hline Total scale & 106.4 & 1.2 & 109.0 & 1.0 & 0.102 \\
\hline Domain family hygiene & 67.0 & 0.8 & 69.0 & 0.7 & 0.080 \\
\hline Domain eating habits/general practices & 39.5 & 0.5 & 40.4 & 0.4 & 0.192 \\
\hline
\end{tabular}

Abbreviation: MSE indicates mean standard error.

${ }^{a} \rho$ of $\chi^{2}$. 
maternal self-efficacy in breastfeeding (Dodt, Joventino, Aquino, et al., 2015; Jager, Skouteris, Broadbent, et al., 2013; McQueen, Dennis, Stremler, et al., 2011).

As well as breastfeeding, childhood diarrhoea must be understood through maternal participation and perceptions, given that a child is primarily cared for by the mother and the extent to which each mother takes care of their child is ruled by various aspects, family, social, and cultural (Anderson, Morton, Naik, et al., 2007; Bartlett, Mawji, Whitehead, et al., 2005). Thus, maternal factors associated with an increased risk of infant morbidity and mortality from diarrhoea include low socioeconomic status and maternal education, poor health knowledge of the mother, inadequate hygiene practices, and insufficient breastfeeding (Genser, Strina, Teles, et al., 2006; Huq \& Tasnim, 2008). In addition to these factors, low-maternal self-efficacy is also associated with the occurrence of childhood diarrhoea (Joventino et al., 2012). Thus, mothers need to believe that their actions can produce the results they want; otherwise, they will have little incentive to act or persevere in the face of difficulties (Bandura, 2012). In this context, health professionals, especially nurses, should insert the concept of maternal self-efficacy in child care, as well as in health education strategies related to the prevention of childhood diarrhoea (Caruso, Stephenson, \& Leon, 2010; Joventino et al., 2012).

In this study, it was observed that the average scores in the EAPDI domain of family hygiene increased more and more consistently in the intervention than the CG. As for the domain of eating habits/general practices, in both group scores showed increasing self-efficacy until the second month postintervention, while there was a slight decrease in the third month.

Some research entails on interventions for the prevention of diarrhoea just to focus on the perspective of hygiene (Dreibelbis, Freeman, Greene, et al., 2014; Galvez, Neish, Balabarca, et al., 2010; Jenkins, Anand, Revell, et al., 2013) or diarrhoea case management, such as the use of ORS (Ghimire, Pradhan, \& Maskey, 2010; Habib, Soofi, Sadiq, et al., 2013). However, other factors can interfere in the prevalence of childhood diarrhoea, such as the care with food (Agustina, Sari, Satroamidjojo, et al., 2013). Hygiene, and especially hand washing, helps to protect children from the 2 major causes of child mortality: diarrhoea and lower respiratory tract infection (Aiello, Coulborn, Perez, et al., 2008; Aiello \& Larson, 2002; Rabie \& Curtis, 2006; World Health Organization, 2005), which together kill more than 3.5 million children under 5 years of age each year (Luby, Agboatwalla, Feikin, et al., 2005). Regarding eating habits/general practices, it is known that the incidence of diarrhoea increases after the introduction of complementary food, due to lack of hygiene in food preparation, especially in children aged between 6 to 24 months (United States Agency for International Development, 2005). The combined effects of inadequate sanitation, unsafe water supplies, and poor personal hygiene are responsible for about $88 \%$ of child deaths due to diarrhoea (United Nations Children's Fund, 2009). Infant feeding must therefore be one of the pillars to prevent infant diarrhoea. In Brazil, a cluster randomised controlled trial investigated the impact of a children's diet programme in health units for breastfeeding practices and incidence of childhood diarrhoea. This identified that children with diarrhoea had more hospitalizations $(P<.001)$, and this was more common for children with shorter exclusive breastfeeding periods (Bernardi, Gama, \& Vitolo, 2011). Regarding infant diarrhoea, a study in Tanzania, Africa, evaluated maternal self-efficacy to prevent this by agreeing with the following declaration "I can hinder my child from having diarrhoea." This research demonstrated that mothers with greater self-efficacy were 1.642 times more likely to use methods of water treatments $(P=.053)$ than others. Furthermore, people that believed they were able to prevent diarrhoea in children were 1.5 times more likely to practice measures of hygiene and to use oral saline solution for rehydration $(P=.107$; .117) (Liu, 2009). In Indonesia, although mothers had knowledge of preventive practices for childhood diarrhoea, most did not develop appropriate behaviours related to hygiene and food practices in the care of children (Usfar, Iswarawanti, Davelyna, et al., 2010). In the interim, nurses should elaborate strategies to promote health education with mothers, providing adequate knowledge about exclusive breastfeeding, hygiene, and sanitation to increase the chances of survival for children under 5 years of age (Popoola \& Mchunu, 2015).

Thus, studies emphasize the need to address self-efficacy in the construction of educational videos for prevention of childhood diarrhoea, to support exchange of knowledge with families (Nascimento, Joventino, Andrade, et al., 2014). Furthermore, social problems can contribute to minimize maternal self-efficacy regarding childhood diarrhoea, requiring alternative approaches so that, even in the face of adverse conditions, mothers can promote the health of their children in the best possible way. Thus, the educational video is an intervention that goes beyond simple sharing of information since it seeks to improve maternal self-efficacy, which is essential for the daily application of the acquired knowledge, promoting behavioural changes to prevent childhood diarrhoea.

The present study contributes knowledge to strengthen the discussion in the face of few articles that cover the execution of randomised clinical studies using educational strategies to prevent diarrhoea. Whilst the study demonstrated significant change in self-efficacy, it is possible that this may have been influenced by multiple simple analyses. Future studies could consider use of more sophisticated forms of analysis.

\section{6 | CONCLUSIONS}

The video that is the subject of this research facilitated the care provided by health professionals, especially by nurses, to promote maternal self-efficacy and assist in guidance on preventing childhood diarrhoea. This trial demonstrated that information delivered by the video was of practical benefit for recipients. Further studies could continue to explore how nurses can use this approach and build on these findings to support mothers in the prevention of childhood diarrhoea.

\section{CONFLICT OF INTEREST}

The authors declare no conflict of interest and confirm that all listed authors meet the authorship criteria and that all authors are in agreement with the content of the manuscript. 


\section{REFERENCES}

Abu-Baker, N. N., Gharaibeh, H. F., Al-Zoubi, H. M., Savage, C., \& Gharaibeh, M. K. Mothers' knowledge and practices of managing minor illnesses of children under five years. Journal of Research in Nursing 2012; 18: 651-666. doi: 10.1177/1744987112451576

Agustina, R., Sari, T. P., Satroamidjojo, S., Bovee-Oudenhoven, I. M. J., Feskens, E. J. M., \& Kok, F. J. (2013). Association of food-hygiene practices and diarrhoea prevalence among Indonesian young children from low socioeconomic urban areas. BioMed Central Public Health. doi: 10.1186/1471-2458-13-977

Aiello, A. E., \& Larson, E. L. (2002). What is the evidence for a causal link between hygiene and infections? The Lancet. Infectious Diseases, 2, 103-110.

Aiello, A. E., Coulborn, R. M., Perez, V., \& Larson, E. L. (2008). Effect of hand hygiene on infectious disease risk in the community setting: A metaanalysis. American Journal of Public Health, 98, 1372-1381. doi: 10.2105/AJPH.2007.124610

Anderson, F. W., Morton, S. U., Naik, S., \& Gebrian, B. (2007). Maternal mortality and the consequences on infant and child survival in rural Haiti. Maternal and Child Health Journal, 11, 395-401. doi: 10.1007/s10995-006-0173-0

Arango, H. G. (2009). Bioestatística: Teórica e computacional. Rio de Janeiro: Guanabara Koogan.

Bandura, A. (2012). On the functional properties of perceived self-efficacy revisited. Journal of Management, 38, 9-44. doi: 10.1177/0149206 311410606

Bartlett, L. A., Mawji, S., Whitehead, S., Crouse, C., Dalil, S., Ionete, D., ... Afghan Maternal Mortality Study Team. (2005). Where giving birth is a forecast of death: Maternal mortality in four districts of Afghanistan, 1999-2002. Lancet, 365, 864-870. doi: 10.1016/S0140-6736(05) 71044-8

Bernardi, J. R., Gama, C. M., \& Vitolo, M. R. (2011). An infant feeding update program at healthcare centers and its impact on breastfeeding and morbidity. Cadernos de Saúde Pública, 27, 1213-1222. doi: 10.1590/S0102311X2011000600018

Caruso, B., Stephenson, R., \& Leon, J. S. (2010). Maternal behavior and experience, care access, and agency as determinants of child diarrhea in Bolivia. Revista Panamericana de Salud Pública, 28, 429-439.

Cullum, N., Ciliska, D., Haynes, R. B., \& Marks, S. (2010). Enfermagem baseada em evidências. Artmed: Porto Alegre.

Dodt, R. C. M., Joventino, E. S., Aquino, P. S., Almeida, P. C., \& Ximenes, L. B. (2015). An experimental study of an educational intervention to promote maternal self-efficacy in breastfeeding. Revista Latino-Americana de Enfermagem, 23, 725-732. doi: 10.1590/0104-1169.0295.2609

Dreibelbis, R., Freeman, M. C., Greene, L. E., Saboori, S., \& Rheingans, R. (2014). The impact of school water, sanitation, and hygiene interventions on the health of younger siblings of pupils: A cluster-randomised trial in Kenya. American Journal of Public Health, 104, e91-e97. doi: 10.2105/AJPH.2013.301412

Galvez, C. A., Neish, C., Balabarca, Y., \& Serrano, L. C. (2010). Programa educacional efectivo en la formación de agentes comunitarios de salud voluntarios en Lima, Perú. Global Health Promotion, 17, 82-91. doi: 10.1177/1757975910365266

Genser, B., Strina, A., Teles, C. A., Prado, M. S., \& Barreto, M. L. (2006). Risk factors for childhood diarrhoea incidence: Dynamic analysis of a longitudinal study. Epidemiology, 17, 658-667. doi: 10.1097/01. ede.0000239728.75215.86

Ghimire, M., Pradhan, Y. V., \& Maskey, M. K. (2010). Community-based interventions for diarrhoeal diseases and acute respiratory infections in Nepal. Bulletin of the World Health Organization, 88, 216-221. doi: 10.2471/BLT.09.065649

Habib, M. A., Soofi, S., Sadiq, K., Samejo, T., Hussain, M., Mirani, M., ... Bhutta, Z. A. (2013). A study to evaluate the acceptability, feasibility and impact of packaged interventions ("Diarrhoea Pack") for prevention and treatment of childhood diarrhoea in rural Pakistan. BioMed Central Public Health. doi: 10.1186/1471-2458-13-922
Huq, M. N., \& Tasnim, T. (2008). Maternal education and child healthcare in Bangladesh. Maternal and Child Health Journal, 12, 43-51. doi: 10.1007/s10995-007-0303-3

Isanaka, S., Elder, G., Schaefer, M., Vasset, B., Baron, E., \& Grais, R. F. (2012). Bridging the gap from knowledge to delivery in the control of childhood diarrhoea. Bulletin of the World Health Organization, 90, 635-635A. doi: 10.2471/BLT.12.109504

Jager, E., Skouteris, H., Broadbent, J., Amir, L., \& Mellor, K. (2013). Psychosocial correlates of exclusive breastfeeding: A systematic review. Midwifery, 29, 506-518. doi: 10.1016/j.midw.2012.04.009

Jenkins, M. W., Anand, A. R., Revell, G., \& Sobsey, M. D. (2013). Opportunities to improve domestic hygiene practices through new enabling products: A study of handwashing practices and equipment in rural Cambodia. International Health, 5, 295-301. doi: 10.1093/inthealth/ int026

Joventino, E. S. (2013). Elaboração e validação de vídeo educativo para promoção da autoeficácia materna na prevenção da diarreia infantil [doctoral dissertation]. Fortaleza: Universidade Federal do Ceará.

Joventino, E. S., Ximenes, L. B., Almeida, P. C., \& Oria, M. O. (2012). The Maternal Self-efficacy Scale for Preventing Early Childhood Diarrhoea: Validity and reliability. Public Health Nursing, 30, 150-158. doi: 10.1111/j.15251446.2012.01042.x

Liu, J. (2009). Maternal beliefs and behaviors in the prevention of childhood diarrhoea in Dar es Salaam, Tanzania [doctoral dissertation]. Stanford: Stanford University.

Luby, S. P., Agboatwalla, M., Feikin, D. R., Painter, J., Billhimer, W., Altaf, A., \& Hoekstra, R. M. (2005). Effect of hand washing on child health: A randomised controlled trial. Lancet, 366, 225-233. doi: 10.1016/ S0140-6736(05)66912-7

McQueen, K. A., Dennis, C. L., Stremler, R., \& Norman, C. D. (2011). A pilot randomised controlled trial of a breastfeeding self-efficacy intervention with primiparous mothers. Journal of Obstetric, Gynecologic, and Neonatal Nursing, 40, 35-46. doi: 10.1111/j.1552-6909.2010.01210.x

Mendes, P. S. A., Ribeiro, H. C., \& Mendes, C. M. C. (2013). Temporal trends of overall mortality and hospital morbidity due to diarrhoeal disease in Brazilian children younger than 5 years from 2000 to 2010. Jornal de Pediatria, 89, 315-325. doi: 10.1016/j.jpedp.2012.10.011

Nascimento, L. A., Joventino, E. S., Andrade, L. C. O., Gomes, A. L. A., \& Ximenes, L. B. (2014). Evaluation of educational videos produced in Brazil about childhood diarrhoea: A documental study. Online Brazilian Journal of Nursing, 13, 311-320. doi: 10.5935/1676-4285.20144702

Popoola, T., \& Mchunu, G. (2015). Application of PRECEDE-PROCEED model to tackle problems identified with diarrhoea burden among under-5 $\mathrm{s}$ in Botswana. International Journal of Nursing Practice, 21, 67-70. doi: 10.1111/ijn.12328

Rabie, T., \& Curtis, V. (2006). Handwashing and risk of respiratory infections: A quantitative systematic review. Tropical Medicine \& International Health, 11, 258-267. doi: 10.1111/j.1365-3156.2006.01568.x

Sampieri, R. H., Collado, C. F., \& Lucio, P. B. (2006). Metodologia de Pesquisa. Editora Mc Graw-Hill: São Paulo.

United Nations Children's Fund (2009). World Health Organization. Diarrhoea: Why children are still dying and what can be done. United Nations Children's Fund, World Health Organization: New York/Geneva.

United Nations Children's Fund (2012a). The State of the World's Children 2012: Children in an urban world. New York: United Nations Children's Fund.

United Nations Children's Fund (2012b). Pneumonia and diarrhoea: Tackling the deadliest diseases for the world's poorest children. New York: United Nations Children's Fund.

United States Agency for International Development (2005). United Nations Children's Fund. World Health Organization. Diarrhoea treatment guidelines including new recommendations for the use of ORS and zinc supplementation for clinic-based healthcare workers. Arlington: The MOST Project. 
Usfar, A. A., Iswarawanti, D. N., Davelyna, D., \& Dillon, D. (2010). Food and personal hygiene perceptions and practices among caregivers whose children have diarrhoea: A qualitative study of urban mothers in Tangerang, Indonesia. Journal of Nutrition Education and Behavior, 42, 33-40. doi: 10.1016/j.jneb.2009.03.003

World Health Organization (2005). World Health Report 2005: Make every mother and child count. Geneva: World Health Organization.

World Health Organization (2013). Ending preventable child deaths from pneumonia and diarrhoea by 2025: The integrated Global Action Plan for Pneumonia and Diarrhoea (GAPPD). Geneva: World Health Organization.

How to cite this article: Joventino ES, Ximenes LB, da Penha JC, Andrade LCO, de Almeida PC. The use of educational video to promote maternal self-efficacy in preventing early childhood diarrhoea. Int J Nurs Pract. 2017; e12524. doi: 10.1111/ ijn.12524 